\title{
PSICOLOGIA E RELIGIÃO: INTELECTUAIS CRISTÃOS ESCREVEM SOBRE FÉ E CIÊNCIA. ${ }^{1}$
}

\author{
Psychology and Religion: Christian intellectual write about faith and science
}

\author{
Edilson Soares de Souza \\ Doutor em História e docente nas Faculdades Batista do Paraná \\ edilsonssouza@uol.com.br.
}

\begin{abstract}
RESUMO: Psicologia e religião despertam o interesse dos diversos segmentos constituintes da sociedade brasileira. A relação entre psicologia e religião é estudada nas mais diversas esferas da religião, como também é objeto de estudo nos meios acadêmicos, que buscam compreender empiricamente as implicações desta relação, algumas vezes tensa, mas também harmoniosa. A proposta do presente texto é apresentar uma reflexão sobre a relação entre psicologia e religião, tomando como fonte de análise as contribuições de dois escritores cristãos. De um lado está o reverendo Eduardo Carlos Pereira (1855-1923), que deixou o catolicismo romano para filiar-se ao presbiterianismo brasileiro. Do outro está o padre jesuíta Leonel Franca (1893-1948), que se destacou como reitor da Pontifícia Universidade Católica do Rio de Janeiro. Os debates entre os dois escritores cristãos ocorreram no contexto de um Estado não confessional, entre o final do século XIX e parte do século XX.
\end{abstract}

Palavras-chave: Psicologia da Religião; Protestantismo; Catolicismo Romano.

ABSTRACT : Psychology and religion arouse the interest of many constituent segments of Brazilian society. The relationship between psychology and religion is studied in many different scopes of religion, as it is also the object of study in academic circles, seeking to empirically understand the implications of this relationship, sometimes stringent, but also harmonious. The purpose of the following research is to introduce an observation of the relationship between psychology and religion, considering the contributions of two Christian writers as sources of analysis. On the one hand is the Rev. Eduardo Carlos Pereira (1855-1923), who left the Roman Catholicism to join the Brazilian Presbyterianism. On the other is Jesuit Fr. Leonel Franca (1893-1948), who stood out as director of the Pontifical Catholic University of Rio de Janeiro. The discussions between the two Christian writers occurred in the context of a non-confessional state, between the late nineteenth century and of the twentieth century.

Keywords: Psychology of Religion; Protestantism; Roman Catholicism.

\footnotetext{
${ }^{1} \mathrm{O}$ presente texto é parte do estudo desenvolvido no Pós-doutorado em História pela Universidade Federal do Paraná (2014-2015), intitulado Psiquismo humano e subjetividades: intelectuais cristãos debatem a influência da religião no processo civilizador e no desenvolvimento mental (Brasil, 18961934).
} 


\section{Introdução}

Um acontecimento político ajudou a mudar parte da trajetória da sociedade brasileira no final do século XIX: a Proclamação da República, que ocorreu em 1889. Tal acontecimento não repercutiu somente nos meandros políticos e institucionais do Estado brasileiro, mas também nas esferas acadêmica e religiosa. Pelo viés político, com a República, o Estado declarou-se não confessional e assegurou a garantia de liberdade de culto e expressão religiosa para todos os credos. A ideia de um Estado não confessional é discutida no livro Cristãos em confronto: Brasil, 1890-1960, quando "se pode notar como católicos e protestantes (batistas e presbiterianos) deram significado aos eventos políticos que marcaram a passagem da Monarquia para a República, num processo de tomada de posse das garantias constitucionais dadas pelo Estado".2

Outro fenômeno que pode ser observado a partir da Proclamação da República foi a ênfase na educação. Ela, que esteve atrelada a Igreja Católica Apostólica Romana durante um longo tempo, passou a ser responsabilidade precípua do Estado, sem a influência direta da religião cristã, caracterizando o fim do padroado. A educação no Brasil experimentou outros patamares, inclusive, quanto ao incentivo de uma formação em nível superior, ampliando a qualificação profissional e favorecendo o intercâmbio entre os acadêmicos brasileiros e os pesquisadores de outras instituições. No entanto, na década de 1930, Sérgio Buarque de Holanda lembrava que "as nossas academias diplomam todos os anos centenas de novos bacharéis, que só excepcionalmente farão uso, na vida prática, dos ensinamentos recebidos durante o curso", já que se observava certa inclinação para as profissões liberais. ${ }^{3}$

Com a República deu-se outro fenômeno importante, marcado pela chegada e permanência de missionários protestantes, presentes no Brasil desde o século XIX. Se durante o Império algumas religiões foram toleradas, foi também neste período que algumas denominações de confissão cristã acatólicas puderam se instalar e expandir as suas atividades confessionais. O confronto discursivo foi inevitável e até mesmo desejado em muitos momentos, pois permitiu a exposição do pensamento e das atividades religiosas dos grupos minoritários, além de estabelecer a diferença entre os ensinamentos do catolicismo romano e aqueles ministrados pelas demais denominações cristãs.

${ }^{2}$ SOUZA, Edilson Soares de. Cristãos em confronto: Brasil, 1890-1960. Curitiba, PR: Editora CRV, 2014, p. 19.

${ }^{3}$ HOLANDA, Sérgio Buarque de. Raízes do Brasil. 26.ed. São Paulo: Companhia das Letras, 2008, p. 156. 
Assim, pode-se empreender uma análise da Psicologia da Religião no Brasil, reconhecendo a importância que a Proclamação da República significou para as diversas religiões no Brasil, entre elas, as múltiplas denominações de confissão cristã, representadas pelos pensadores do catolicismo romano e do protestantismo. Cabe lembrar, no entanto, que a relevância não está no evento "República" em si mesmo, mas no sentido que os intelectuais cristãos deram ao acontecimento político naquele final do século XIX.

Desta forma, uma pergunta pode nortear a discussão a seguir: como os intelectuais cristãos, tanto do catolicismo romano quanto do protestantismo, perceberam a relação entre religião e psicologia, tomando como fonte de análise os textos polêmicos? O objetivo da presente reflexão, visando responder a pergunta colocada, foi compreender a relação entre religião e psicologia - ou psicologia e religião -, tomando como base de análise os debates firmados entre dois autores do cristianismo no Brasil: o reverendo presbiteriano Eduardo Carlos Pereira (1855-1923), autor de O problema religioso da América Latina (1920) e o padre jesuíta Leonel Franca (1893-1948), que escreveu Psicologia da Fé (1934). Neste sentido, utiliza-se a produção literária de polêmica religiosa como instrumento para a compreensão da relação entre religião cristã e psicologia, considerando-se a sociedade brasileira entre o final do século XIX e as primeiras décadas do século XX.

\section{O ambiente para o desenvolvimento das polêmicas religiosas no Brasil}

Desde o seu início, o processo político de colonização no Brasil esteve atrelado a outro esforço, que objetivava converter em cristãos os nativos e aqueles que aqui aportassem, transformando a sociedade numa extensão do cristianismo praticado em Portugal, aproximando o Império do clero católico romano. O resultado deste projeto político-religioso, para a sociedade brasileira, foi a presença majoritária do catolicismo romano, com sua influência em diversas instâncias sociais ao longo de quatro séculos, o que não se traduziu num catolicismo uniforme, como também não ocorreu a formação de um cristianismo homogêneo.

O poder atribuído e conferido a Igreja Católica Apostólica Romana foi reduzido com a República, já que todas as religiões inseridas no Brasil conquistaram o direito de expansão de suas atividades religiosas, como também a liberdade de expor o seu 
pensamento e de praticar os seus rituais. Simultaneamente a condição de um Estado não confessional, a sociedade brasileira continuou marcadamente religiosa, pluralista em suas práticas de fé e capaz de assimilar outras formas ritualísticas de crenças, revelando um sincretismo que se observa até os dias atuais.

Este ambiente caracterizado por práticas religiosas desde 1500, que foi se modificando com a chegada de outras religiões, constituiu-se num ambiente favorável para o desenvolvimento de diálogos entre diferentes formas de fé, mas também para o desenvolvimento das significativas polêmicas religiosas, inclusive, no interior do cristianismo, representado em suas múltiplas denominações. O Brasil do século XIX apresentava, então, as marcas das transformações, tanto pelo viés político-científico quanto pelo viés religioso, inclusive, pelos confrontos religiosos. Tais confrontos discursivos foram impulsionados pelas publicações com conteúdo apologista, mas também com traços de uma esperada e evidente polêmica religiosa.

É importante lembrar que,

os confrontos religiosos ganham um significado diferente, para além dos
embates entre rivais opositores, que num primeiro momento podem indicar
uma incoerência dos pressupostos do cristianismo, que proclamam a máxima
do amor ao semelhante. Nesse sentido, estes não são percebidos apenas como
disputas teológicas e dogmáticas, mas como instrumentos estratégicos para se
alcançar a (re) organização e o avanço estratégicos das várias denominações,
que se beneficiaram da igualdade promulgada pelas leis do Estado
republicano, no início da década de $1890 .{ }^{4}$

Dois aspectos, portanto, devem ser considerados: a) os confrontos entre intelectuais cristãos não devem ser interpretados como disputas egocêntricas no interior da religião cristã, como se apenas catolicismo e protestantismo gastassem tempo com questiúnculas de menor importância, inclusive, para toda a sociedade brasileira; b) a análise dos confrontos religiosos pode apontar - metodologicamente - para outras questões, como a reorganização do catolicismo no Brasil, a expansão do protestantismo na América Latina, e a maneira como alguns religiosos e escritores daquele período pensaram a influência de determinada forma de religião sobre o desenvolvimento humano e sobre as funções mentais.

Foi neste cenário que surgiram dois intelectuais que se destacaram na produção de literatura apologética e polemista: Eduardo Carlos Pereira e Leonel Franca. Sobre o

\footnotetext{
${ }^{4}$ SOUZA, Edilson Soares de. Cristãos em confronto: Brasil, 1890-1960. Curitiba, PR: Editora CRV, 2014, p. 18.
} 
primeiro, é importante destacar que, após questionar e deixar o catolicismo, se tornou um dos principais líderes do protestantismo, sobretudo, no contexto denominacional presbiteriano. Pereira questionou o trabalho missionário realizado pela Igreja Católica no Brasil, colocando-se como um apoiador dos esforços missionários das denominações protestantes, já que entendeu que o catolicismo havia fracassado em sua missão de cristianizar o povo brasileiro. Depois de atuar destacadamente na Igreja Presbiteriana do Brasil, rompeu com a denominação e formou, ao lado de outros líderes, a Igreja Presbiteriana Independente do Brasil, sendo esta outra influência do presbiterianismo em solo brasileiro. Sobre Leonel Franca é possível lembrar parte de sua trajetória clerical, já que se tornou, igualmente, um intelectual de destaque no cristianismo brasileiro, produzindo vasta literatura religiosa, com características filosóficas, teológicas e doutrinárias, ajudando na divulgação do pensamento católico no período da República. Em 1940 o padre Leonel Franca foi nomeado o primeiro reitor da Pontifícia Universidade Católica do Rio de Janeiro.

Observa-se, portanto, que o ambiente social no Brasil, entre o século XIX e parte do século $\mathrm{XX}$, propiciou inúmeras mudanças, tanto de ordem política quanto religiosa. Mas aquele período favoreceu também o avanço de outras discussões, destacando-se aquelas que perpassavam as liberdades individuais e o papel do Estado no desenvolvimento da sociedade. Parte desta discussão, que remete também à psicologia, foi analisada pelo prof. Luís Cláudio Mendonça Figueiredo. Com formação em psicologia, Figueiredo desenvolveu significativos estudos em história da psicologia, considerando, entre outros aspectos, A gestação do espaço psicológico no século XIX: Liberalismo, Romantismo e Regime disciplinar. ${ }^{5}$

Para o autor, os três fatores citados - Liberalismo, Romantismo e ênfase na Disciplina - podem ser associados às inquietações que motivaram pensadores das diversas áreas a refletir sobre o indivíduo e as suas relações, tanto consigo mesmo quanto com os outros, inclusive, com o poder atribuído ao Estado. As contribuições filosóficas e culturais também chegaram à esfera da psicologia, que avançou em seus estudos sobre a constituição do ser humano.

Liberalismo e disciplina foram objetos de análise dos especialistas em psicologia, que analisaram a relação entre o individualismo e as tensões geradas pela 
sociedade, cada vez mais "vigiada" por um Estado que alcançava poder em sua coerção social. Esta temática ocupou alguns intelectuais religiosos, que refletiram sobre a importância do individualismo em detrimento do poder depositado em determinadas instituições, inclusive, naquelas de caráter religioso. Se por um lado Eduardo Carlos Pereira defendeu o indivíduo, que tinha liberdade para ler e interpretar o texto sagrado cristão - a Bíblia -, por outro Leonel Franca defendeu a instituição confessional, detentora do capital religioso, sendo a Igreja Católica a única que poderia ler e interpretar os textos bíblicos.

\section{A relação entre religião e psicologia na percepção de escritores religiosos}

Paul Johnson, autor de Psicologia da Religião, aproximou história, sociologia e psicologia da religião, num texto publicado nos Estados Unidos, mas que circulou no Brasil na década de 1960. Johnson pode ser colocado ao lado de outros pensadores que procuraram entender a religião a partir de outros olhares, além da visão que os adeptos apresentavam de suas comunidades de fé. No século XX a religião ganhou mais destaque como objeto de estudo em várias áreas do conhecimento humano, destacandose a psicologia, que a partir de seus pressupostos procurou entender a influência dos fenômenos religiosos no desenvolvimento humano.

Desta forma, em meados do século passado, o autor entendeu que:

o estudo científico da religião inclui a História, a Sociologia e a Psicologia da religião. A História da religião pesquisa as culturas primitivas e as antiguidades sepultadas, a fim de procurar suas mais antigas formas e traçar, através dos séculos, o desenvolvimento da religião. A sociologia da religião investiga o lugar das crenças, no grupo vivente, e examina a interação dos fatôres sociais, econômicos e políticos, com valores religiosos. A psicologia da religião encara a experiência humana em sua essência, para compreender o que a religião significa para as pessoas. ${ }^{6}$

Pode-se afirmar que os estudos sobre a Psicologia da Religião são mais recentes no contexto acadêmico brasileiro. Diferentemente do que ocorreu no Brasil, foi "no ambiente científico e intelectual anglo-saxão, em particular nos Estados Unidos, que se desenvolveu, no último século, uma volumosa pesquisa empírica sobre as implicações

\footnotetext{
${ }^{6}$ JOHNSON, Paul. Psicologia da Religião. São Paulo: ASTE, 1964, p. 14.
} 
psicológicas e psicossociais, tanto das religiões institucionais como da religiosidade em geral". 7

Aspecto importante, no entanto, é observar o interesse empírico demonstrado pela psicologia, que se voltou para os fenômenos religiosos, sem desprezar os rituais realizados pelas religiões tidas como institucionalizadas. Interesse semelhante nota-se com os estudos que contemplam a vivência da fé e da espiritualidade, sem que estas se encontrem atreladas às religiões formais ou institucionais. Percebe-se que "a produção empírica em psicologia da religião revelou, nos últimos 50 a 80 anos, um volume imenso de pesquisas veiculadas por importantes revistas acadêmicas, lideradas geralmente por grupos mesclados de sociólogos, psicólogos, teólogos, pastores e intelectuais em geral". ${ }^{8}$

Aspecto relevante para a psicologia é analisar a influência das múltiplas formas de uma mesma religião no desenvolvimento do indivíduo, partindo de seu nascimento até o término de sua trajetória de vida. Ao tratar da Religião na Infância, Johnson afirmou que "a aprendizagem é motivada por estímulos do ambiente dinâmico, especialmente pelas relações interpessoais. Começa no nascimento e continua até à morte". 9 Dalgalarrondo lembrou mais recentemente que as "crianças apreendem a religião de uma forma, adolescentes de outra, assim como adultos e idosos a praticam e vivenciam de modos diferenciados". ${ }^{10}$ Algo importante na presente reflexão, que remete a análise da produção de dois autores religiosos do cristianismo, é destacar que "parece haver um percurso da religiosidade, com variações na intensidade e na qualidade do envolvimento religioso ao longo do curso da vida". ${ }^{11}$

Outro acadêmico que pode ser colocado ao lado dos teóricos na produção da Psicologia da Religião no Brasil é Merval Rosa. Para Rosa, que escreveu na década de 1990, era importante limitar adequadamente o campo de atuação ou análise desta área da psicologia. Em sua compreensão, "psicologia da religião é o estudo do fenômeno religioso do ponto de vista psicológico, ou seja, a aplicação dos princípios e métodos da psicologia ao estudo científico do comportamento religioso do homem, quer como

\footnotetext{
${ }^{7}$ DALGALARRONDO, Paulo. Religião, psicopatologia e saúde mental. Porto Alegre: Artmed, 2008, p. 77.

${ }^{8}$ DALGALARRONDO, Paulo. Religião, psicopatologia e saúde mental. Porto Alegre: Artmed, 2008, p. 79.

${ }^{9}$ JOHNSON, Paul. Psicologia da Religião. São Paulo: ASTE, 1964, p. 85.

${ }^{10}$ DALGALARRONDO, Paulo. Religião, psicopatologia e saúde mental. Porto Alegre: Artmed, 2008, p. 89.

${ }^{11}$ DALGALARRONDO, Paulo. Religião, psicopatologia e saúde mental. Porto Alegre: Artmed, 2008, p. 89.
} 
indivíduo, quer como membro de uma comunidade religiosa". ${ }^{12} \mathrm{E}$ acrescentou: "psicologia da religião é o estudo descritivo e, tanto quanto possível, objetivo do fenômeno religioso, onde quer que ele ocorra". ${ }^{13}$

Pode-se salientar que a Psicologia da Religião, fundamentando-se em metodologias e pressupostos da psicologia, não tem como objetivo negar ou mesmo desqualificar as várias religiões e as suas práticas ritualísticas, como também não se constitui em instrumento de legitimação das diversas formas religiosas, colocando-se a serviço das forças institucionais representativas das múltiplas religiões. Assim, uma de suas intenções é compreender o fenômeno religioso, partindo de instrumentos empíricos e metodológicos.

Um estudioso importante para os avanços das pesquisas considerando a relação entre religião e psicologia, embora com um perfil mais de escritor religioso do que de um cientista, foi Leonel Franca. Ele faz parte do grupo de pioneiros no Brasil que se dedicou aos estudos da psicologia, produzindo a obra A Psicologia da Fé. O livro de Franca "tem como principal referência a filosofia, a teologia e a biografia de crentes e descrentes", abordando temas como Definição da fé, a aproximação entre A fé e a inteligência, além de discutir $A$ vontade e a fé. Outros aspectos tratados foram: $A$ conquista da fé e a experiência de Conversão, abordados no final de seu livro. ${ }^{14}$

Leonel Franca, tendo como base de sua reflexão a teologia e a filosofia, escreveu sobre a relação entre fé e inteligência, o que interessa aos estudos da Psicologia da Religião. Ele, então, afirmou que "outra é, na doutrina católica, a concepção da fé. Sem desconhecer toda a escala de sentimentos que a podem acompanhar em cada alma, como harmônios que lhe dão o timbre próprio, a fé, na sua essência, é um ato de inteligência, a adesão prestada a uma verdade revelada". ${ }^{15}$ Merece destaque neste texto religioso, publicado na década de 1930, a afirmação de que a fé é um ato de inteligência do ser humano.

No livro, Franca procurou indicar a sua compreensão sobre fé, recordando determinadas posições defendidas pelo cristianismo ao longo de sua trajetória, destacando o lugar que a Igreja Católica ocupou como representante de um conjunto

\footnotetext{
${ }^{12}$ ROSA, Merval. Psicologia da Religião. 3.ed. Rio de Janeiro: JUERP, 1992, p. 15.

${ }^{13}$ ROSA, Merval. Psicologia da Religião. 3.ed. Rio de Janeiro: JUERP, 1992, p. 15.

${ }^{14}$ FRANCA, Leonel. A psicologia da fé e o Problema de Deus. Rio de Janeiro: Ed. PUC-Rio/Edições Loyola, 2001.

${ }^{15}$ FRANCA, Leonel. A psicologia da fé e o Problema de Deus. Rio de Janeiro: Ed. PUC-Rio/Edições Loyola, 2001, p. $14-15$.
} 
dogmático e doutrinário, lembrando que "em todas elas crer apresenta-se-nos como um ato da inteligência que admite uma doutrina, um fato, uma verdade, sob o testemunho de outrem que afirma". ${ }^{16}$ Parece que para Franca, no contexto religioso cristão, a experiência do "crer" podia ter um significado muito próximo da "racionalidade".

Partindo do pressuposto de que a psicologia demonstra significativo interesse pela constituição e desenvolvimento da inteligência, é significativa a proposta de Leonel Franca, quando afirmou que fé e inteligência estão relacionadas e favorecem o crescimento humano. Cabe lembrar, no entanto, que Franca não era um cientista no sentido positivista do termo, buscando comprovações para as suas considerações. Ele era um escritor religioso que procurou defender suas profundas convicções existenciais e doutrinárias. Neste sentido, não se pode ler Eduardo Carlos Pereira, pelo lado protestante, e nem Leonel Franca, defensor do catolicismo romano, a partir de pressupostos tidos como científicos. Eles devem ser tomados como escritores cristãos polemistas, que na passagem do século XIX para o XX elaboraram e publicaram suas percepções da relação que se observou entre religião e psicologia.

Um destaque importante, ainda, é observar que Franca toma a inteligência como uma função inata de cada pessoa, não se propondo discutir sobre a sua gênese e desenvolvimento. Neste sentido, pode-se levantar uma hipótese: Leonel Franca partiu da posição criacionista, defendida pelos dogmas do catolicismo romano, não existindo motivos para refletir sobre a origem da inteligência, já que o ser humano foi criado à imagem e semelhança de Deus. Reforça esta hipótese uma afirmação de José Neivaldo de Souza, quando disse que "Agostinho tentou por toda sua vida encontrar essa imagem de Deus no exterior, mas em tempo percebeu que ela se encontra no interior, na mente". ${ }^{17}$

Do outro lado do debate estava o reverendo Eduardo Carlos Pereira, que também tratou da relação entre religião e psicologia, considerando os elementos da fé e da inteligência humana. Pereira constituiu-se num ferrenho defensor do cristianismo de viés acatólico, apresentando argumentos em favor das propostas do protestantismo para o desenvolvimento social e o crescimento pessoal. Pereira entendeu que a leitura da Bíblia (incentivada e favorecida pelas denominações protestantes no Brasil) era capaz

\footnotetext{
${ }^{16}$ FRANCA, Leonel. A psicologia da fé e o Problema de Deus. Rio de Janeiro: Ed. PUC-Rio/Edições Loyola, 2001, p. 15.

${ }^{17}$ SOUZA, José Neivaldo de. Imagem humana à semelhança de Deus: proposta de antropologia teológica. São Paulo: Paulinas, 2010, p. 54.
} 
de transformar as pessoas e ajudar no progresso social. Opondo-se abertamente ao pensamento católico romano, que vinculava a interpretação dos textos sagrados do cristianismo à função do magistério, Pereira tornou-se, ao lado de outros intelectuais protestantes, um dos defensores da chamada liberdade de consciência, favorecendo ao adepto do protestantismo o acesso ao texto, visando a sua leitura e interpretação.

Se por um lado a inteligência era aprimorada pela fé, na visão de Eduardo Pereira, por outro a inteligência era a instância mental que acolhia a fé religiosa, segundo Leonel Franca. Para ambos, no entanto, era possível aproximar a experiência religiosa da fé ao avanço humano, sobretudo, ao desenvolvimento da inteligência. Novamente é importante lembrar que os dois escritores estão ocupados com os pressupostos religiosos sobre a inteligência, e não com uma forma de medir a inteligência.

Um exemplo do que foi mencionado anteriormente pode ser observado no fragmento textual, cuja obra foi publicada em 1896, quando Pereira escreveu sobre a importância da inteligência para o progresso social.

De acordo com o polemista protestante:

a diffusão das luzes é a primeira condição do progresso. O trabalho é tanto mais productivo, quanto mais intelligente. Demais a instrucção é indispensavel á practica das liberdades constitucionaes. É preciso que o eleitor tenha consciencia de seu voto, sem o que o paiz será mal governado e teremos a inercia ou a desordem. ${ }^{18}$

Eduardo Carlos Pereira, posteriormente, elaborou e publicou uma obra mais complexa de polêmica religiosa, que fomentou discussões acaloradas e tensas em favor e contra os seus argumentos. Em 1920, seguindo uma linha argumentativa em prol do protestantismo e em oposição ao catolicismo romano inserido no Brasil, o reverendo presbiteriano voltou a refutar o magistério católico e incentivou a relevância da leitura da Bíblia no desenvolvimento humano.

Para ele,

a instrucção, pois, é a base da liberdade e prosperidade dos povos. Ora, é sabido que os paizes protestantes levam immensa dianteira em instrucção aos paizes catholicos romanos. A razão é clara: o culto reformado repousa sobre

\footnotetext{
${ }^{18}$ PEREIRA, Eduardo Carlos. O Protestantismo é uma Nullidade: polemica religiosa. São Paulo: Typographia
} Aurora, 1896, p. 20. 
um livro - a Biblia, o protestante deve, pois, saber ler. O culto catholico repousa sobre os sacramentos e sobre certas practicas que não exigem leitura. Saber ler não é necessário, é antes um perigo, porque abala o principio de obediencia passiva sobre o qual se apoia todo o edificio catholico: a leitura é caminho que conduz á heresia. Por isso, a organização da instrucção popular data da Reforma. ${ }^{19}$

Ao defender o catolicismo, Leonel Franca apresentou uma visão singular sobre o que se chamou "problema religioso" no contexto da América Latina. Para o jesuíta, a existência de um "problema religioso", que foi questionado no livro A Igreja, a Reforma e a Civilização, não tinha raízes na influência do protestantismo ou do catolicismo no progresso social. No entanto, para o escritor católico, havia um "problema religioso" na América Latina, mas o mesmo deveria ser visto e colocado por outro prisma.

De acordo com Franca,
não é o que pensa o Sr. C. Pereira. Não se trata de alternativa de escolha entre o catolicismo e o protestantismo. Nosso problema religioso cifra-se na intensificação da vida católica no país. Cumpre reparemos os erros dos nossos maiores. O império, inspirado numa política liberal de vistas acanhadas, encadeou a atividade expansiva da Igreja. A república, iludida pelos falsos reflexos de uma liberdade de consciência mal entendida, eliminou a influência religiosa da vida oficial do govêrno. Contraminemos os efeitos dêstes desacertos. Trabalhemos por inocular nas massas populares a consciência austera dos seus deveres cristãos. Restituamos à escola a instrução religiosa, base insubstituível da educação moral e cívica. Saneemos a nossa política e a nossa administração, fortalecendo nas almas os princípios eficazes da justiça e da abnegação social. Infundamos nas nossas leis o espírito vivificador do cristianismo. $\mathrm{O}$ direito de um povo deve espelhar a sua religião; a consciência jurídica de um país deve ser o reflexo de sua consciência religiosa. ${ }^{20}$

Observa-se que o escritor do catolicismo conclamou o Estado e as instituições constituintes da sociedade no sentido de trabalharem para "inocular nas massas populares a consciência austera dos seus deveres cristãos". ${ }^{21} \mathrm{E}$ fez um apelo objetivando um processo de formação do indivíduo fundamentado no cristianismo: "restituamos à escola a instrução religiosa, base insubstituível da educação moral e cívica", ${ }^{22}$

Afinal, notou o padre jesuíta,

entre as certezas, porém, a fé ocupa um lugar distinto que só lhe poderemos assinalar com um exame mais detido dessa atitude intelectual. O que distingue a certeza é, como vimos, a determinatio intellectus ad unum,

\footnotetext{
${ }^{19}$ PEREIRA, Eduardo Carlos. O Protestantismo é uma Nullidade: polemica religiosa. São Paulo: Typographia Aurora, 1896, p. 20.

${ }^{20}$ FRANCA, Leonel. A Igreja, a Reforma e a Civilização. 6.ed. Rio de Janeiro: Livraria Agir Editora, 1952, p. 461462.

${ }^{21}$ FRANCA, Leonel. A Igreja, a Reforma e a Civilização. 6.ed. Rio de Janeiro: Livraria Agir Editora, 1952, p. 461462.

${ }^{22}$ FRANCA, Leonel. A Igreja, a Reforma e a Civilização. 6.ed. Rio de Janeiro: Livraria Agir Editora, 1952, p. 461 462 .
} 
determinação provocada por um motivo que, excluindo a dúvida e a hesitação, constitui uma garantia incontestável de que a nossa afirmação está com a verdade. Este motivo outro não é senão a manifestação do próprio objeto, a sua claridade que ilumina a inteligência, numa palavra, a sua evidência. A análise das diversas formas sob as quais se pode apresentar a evidência nos permitirá uma classificação racional das diferentes espécies de certeza. ${ }^{23}$

\title{
Considerações
}

As obras citadas no presente texto - O Protestantismo é uma nullidade: polemica religiosa e A psicologia da fé - ajudam a compreender parte dos discursos religiosos de dois intelectuais do cristianismo, que trataram de temas como Religião e Psicologia. É importante salientar que Eduardo Carlos Pereira e Leonel Franca produziram textos de cunho religioso ou teológico, não existindo por parte dos escritores cristãos uma preocupação metodológica puramente científica. Desta forma, a partir da literatura religiosa, busca-se compreender os diálogos entre psicologia e religião, tomando como base os debates realizados por escritores cristãos.

Ambos defenderam, debateram e escreveram sobre temas que indicavam uma forma de cristianismo - orientada pelo protestantismo ou pelo catolicismo romano -, sendo capaz de moldar o indivíduo a partir de determinadas práticas religiosas. Ao debaterem, Pereira e Franca podem ser colocados ao lado de outros intelectuais que também analisaram a relação entre psicologia e religião, como Sigmund Freud e Carl Gustav Jung.

Jung escreveu sobre a relação entre religião e psicologia, afirmando:

\begin{abstract}
visto que a religião constitui, sem dúvida alguma, uma das expressões mais antigas e universais da alma humana, subentende-se que todo o tipo de psicologia que se ocupa da estrutura psicológica da personalidade humana deve pelo menos constatar que a religião, além de ser um fenômeno sociológico ou histórico, é também um assunto importante para grande número de indivíduos. ${ }^{24}$
\end{abstract}

Objetivou-se, no presente texto, propor uma reflexão sobre a relação entre religião cristã e psicologia, partindo da contribuição de dois autores religiosos, que se ocuparam mais em apologias e polêmicas doutrinárias e teológicas, do que com o embasamento empírico de suas observações. No que pese não serem considerados estudiosos de uma psicologia que procurava ser empírica, ambos ajudaram a pensar nas aproximações e nos distanciamentos que envolvem psicologia e religião. Um segundo objetivo foi apontar para outras fontes de análise para a compreensão da Psicologia da

${ }^{23}$ FRANCA, Leonel. A psicologia da fé e o Problema de Deus. Rio de Janeiro: Ed. PUC-Rio/Edições Loyola, 2001, p. 21.

${ }^{24}$ JUNG, Carl Gustav. Psicologia e religião. 10.ed. Petrópolis: Vozes, 2012, p. 17. 
Religião, entendendo que a literatura religiosa de estilo polemista pode ajudar em outras reflexões sobre a relação entre formas religiosas e psicologia.

\section{Referências}

DALGALARRONDO, Paulo. Religião, psicopatologia e saúde mental. Porto Alegre: Artmed, 2008.

FIGUEIREDO, Luís Cláudio Mendonça. A invenção do psicológico: quatro séculos de subjetivação (1500-1900). 7.ed. São Paulo:Escuta, 2007.

FRANCA, Leonel. A psicologia da fé e o Problema de Deus. Rio de Janeiro: Ed. PUC-Rio/Edições Loyola, 2001.

FRANCA, Leonel. A Igreja, a Reforma e a Civilização. 6.ed. Rio de Janeiro: Livraria Agir Editora, 1952.

HOLANDA, Sérgio Buarque de. Raízes do Brasil. 26.ed. São Paulo: Companhia das Letras, 2008.

JOHNSON, Paul. Psicologia da Religião. São Paulo: ASTE, 1964.

JUNG, Carl Gustav. Psicologia e religião. 10.ed. Petrópolis: Vozes, 2012.

PEREIRA, Eduardo Carlos. O problema religioso da America Latina: estudo dogmatico-historico. São Paulo: Empresa Editora Brasileira, 1920.

PEREIRA, Eduardo Carlos. O Protestantismo é uma Nullidade: polemica religiosa. São Paulo: Typographia Aurora, 1896.

ROSA, Merval. Psicologia da Religião. 3.ed. Rio de Janeiro: JUERP, 1992.

SOUZA, Edilson Soares de. Cristãos em confronto: Brasil, 1890-1960. Curitiba, PR: Editora CRV, 2014.

SOUZA, José Neivaldo de. Imagem humana à semelhança de Deus: proposta de antropologia teológica. São Paulo: Paulinas, 2010.

Recebido: 14/06/2015

Received: 06/14/2015

Aprovado: :09/07/2015

Approved: 07/09/2015 